\title{
Immigrant status and increased risk of heart failure: the role of hypertension and life-style risk factors
}

Yan Borné ${ }^{*}$, Gunnar Engström¹, Birgitta Essén² and Bo Hedblad ${ }^{1}$

\begin{abstract}
Background: Studies from Sweden have reported association between immigrant status and incidence of cardiovascular diseases. The nature of this relationship is unclear. We investigated the relationship between immigrant status and risk of heart failure (HF) hospitalization in a population-based cohort, and to what extent this is mediated by hypertension and life-style risk factors. We also explored whether immigrant status was related to case-fatality after HF.

Methods: 26,559 subjects without history of myocardial infarction (MI), stroke or HF from the community-based Malmö Diet and Cancer (MDC) cohort underwent a baseline examination during 1991-1996. Incidence of HF hospitalizations was monitored during a mean follow-up of 15 years.

Results: 3,129 (11.8\%) subjects were born outside Sweden. During follow-up, 764 subjects were hospitalized with HF as primary diagnosis, of whom 166 had an Ml before or concurrent with the HF. After adjustment for potential confounding factors, the hazard ratios (HR) for foreign-born were 1.37 (95\% Cl: 1.08-1.73, $p=0.009$ ) compared to native Swedes, for HF without previous MI. The results were similar in a secondary analysis without censoring at incident Ml. There was a significant interaction $(p<0.001)$ between immigrant status and waist circumference (WC), and the increased HF risk was limited to immigrants with high WC. Although not significant foreign-born tended to have lower one-month and one-year mortality after HF.
\end{abstract}

Conclusions: Immigrant status was associated with long-term risk of HF hospitalization, independently of hypertension and several life-style risk factors. A significant interaction between WC and immigrant status on incident HF was observed.

Keywords: Immigrant status, heart failure, risk factors, cohort study, case-fatality, epidemiology

\section{Background}

Heart failure (HF) is one of the leading causes for morbidity and mortality, particularly in the elderly. Hypertension and myocardial infarction (MI) are the main causes of HF in the general population [1-5]. Other important risk factors that have been associated with incidence of HF include age, male sex, overweight, diabetes, smoking, physical inactivity, alcohol consumption, inflammatory and socioeconomic factors [2,6-13].

\footnotetext{
* Correspondence: Yan.Borne@med.lu.se

'Department of Clinical Sciences, Cardiovascular Epidemiology, Skåne

University Hospital, Lund University, 20502 Malmö, Sweden

Full list of author information is available at the end of the article
}

It has repeatedly been shown that immigrants in Sweden have higher risk of coronary heart disease and stroke compared to Swedish-born subjects [14-17]. In a previous study of the entire population of Malmö, Sweden, we found substantial differences in risk of HF hospitalization among foreign-born subjects [18]. In that study, increased incidence of HF hospitalizations was found in immigrants from Finland, Former Yugoslavia and Hungary. However, it is still unclear to what extent the increased risk in these groups could be explained by major biological and lifestyle risk factors for HF, e.g., hypertension, overweight, and smoking.

Thus, the purpose of the present study was to further explore the association of immigration status and risk of

\section{Biomed Central}


HF hospitalization in an urban population-based cohort and to what extent the relationship is explained by conventional cardiovascular risk factors. We also explored whether immigrant status was related to case-fatality (e.g. 1-month and 1-year, respectively) after HF.

\section{Methods}

\section{Study population}

The Malmö Diet and Cancer (MDC) cohort is a prospective cohort study from the city of Malmö in southern Sweden. Sample characteristics, data collection and clinical definitions for MDC have been described previously [19-21]. Briefly, 28,449 men $(\mathrm{n}=11,246$, born 1923-1945) and women ( $\mathrm{n}=17,203$, born 1923-1950) attended a baseline examination between March 1991 and September 1996. Participants underwent sampling of peripheral venous blood, measurement of blood pressure and anthropometric measures and filled out a selfadministered questionnaire.

Subjects with history of cardiovascular events (coronary events or stroke, $\mathrm{n}=970$ subjects) or HF ( $\mathrm{n}=46$ subjects) at the baseline examination were excluded. In addition, subjects were also excluded due to missing information on blood pressure (BP), waist circumference (WC), smoking habits, alcohol consumption, physical activity, leukocyte counts, educational level, marital status and country of birth. Thus, the final study population in the analysis consisted of 26,559 (10,227, 38.5\% men and 16,332, $61.5 \%$ women) subjects, aged 45-73 years. The study was approved by the ethical committee at Lund University Lund, Sweden, and all participants provided informed consent.

\section{Measurements and definitions}

Information on current use of BP lowering, lipid-lowering or anti-diabetic medications, smoking habits, alcohol consumption, leisure time physical activity, educational level, marital status and country of birth were obtained from a self-administered questionnaire [20]. WC (in cm) was measured midway between the lowest rib margin and iliac crest in the standing position without clothing. WC was stratified into normal WC and high WC $(\geq 94$ $\mathrm{cm}$ for men and $\geq 80 \mathrm{~cm}$ for women) [22]. Blood pressure was measured using a mercury-column sphygmomanometer after 10 minutes of rest in the supine position. Hypertension was defined as blood pressure equal or above $140 / 90 \mathrm{~mm} \mathrm{Hg}$ or current use of blood pressure-lowering medication. Leukocyte concentrations were analysed consecutively in fresh heparinized blood. Diabetes mellitus was defined as fasting whole blood glucose level greater than $109 \mathrm{mg} / \mathrm{dL}$ (e.g. $6.0 \mathrm{mmol} / \mathrm{L}$ ), self-reported physician's diagnosis of diabetes, or use of antidiabetic medications. Subjects were categorized into current smokers (i.e., those who smoked regularly or occasionally) or non-smokers (i.e., former smokers and never smokers). High alcohol consumption was defined as $>40$ gram alcohol per day for men and $>30 \mathrm{~g} /$ day for women. Leisure time physical activity was grouped as lowest quartile or other. As previously described educational level was defined as low education (up to grade 9) and high (> 9 years) [23]. Marital status was categorized into married or unmarried. Immigrant status was grouped as Swedish-born and foreign- born. We were unable to study immigrants from individual countries of birth due to limited numbers of HF cases.

\section{Ascertainment of cardiovascular events and HF}

The Swedish Hospital Discharge Register (SHDR) was used for case retrieval. Validation study has shown that a primary diagnosis of HF in the SHDR has a validity of 95\% [24]. The corresponding figure for MI is 94\% [25]. HF was defined as International Classification of Diseases- $8^{\text {th }}$ revision (ICD-8) code $427.00,427.10$ and 428.99; 428 (ICD-9); and I50, I11 (ICD-10) as the primary diagnosis [24]. Non-fatal MI was defined as 410 (ICD-8 and 9) or I21 (ICD-10) [25]. Information on mortality was obtained through the Swedish Cause of Death Register. All subjects were followed from the baseline examination until a first diagnosis of HF, emigration from Sweden, death or December $31^{\text {st }}, 2008$, whichever came first.

\section{Statistical analysis}

Cox proportional hazards regression was used to examine the association between selected immigrant status and risk of HF hospitalization in the MDC cohort. Hazard ratios (HR), with 95\% confidence interval (CI) were calculated. Age and sex were included as covariates in the basic model. Secondly, we also adjusted for systolic BP, use of BP-lowering medication, lipid-lowering medication, diabetes mellitus, WC, current smoking, high alcohol consumption, low physical activity and leukocyte counts. Possible interactions between immigrant status and age, sex and cardiovascular risk factors on incidence of HF were explored by introducing interaction terms in the multivariate model. The primary analysis was performed with censoring at first nonfatal MI during follow-up, i.e., cases with MI prior to HF were not counted. Secondary analysis included all HF incident cases, regardless of MI. Two-sided p values $<0.05$ were considered significant. The Kaplan-Meier curve was used to illustrate incidence of hospitalization due to HF in relation to immigrant status and waist circumference.

Case-fatality rates were calculated as the proportion of those with a HF hospitalization that died within 1month and 1-year, respectively. Cox proportional hazards regression was used and adjusted for age, sex and year of HF event. All analyses were performed using PASW version 18 (SPSS Inc., Chicago, Illinois). 


\section{Results}

Overall, mean age ( \pm standard deviation) at baseline was $58 \pm 7.6$ years and $61.5 \%$ were women. A total of 23,430 subjects were born in Sweden and 3,129 (11.8\%) were born outside Sweden. Of those born outside Sweden, the majority came from Denmark (10.5\%), Former Yugoslavia (8.3\%), Finland (7.6\%), Germany (8.8\%), Poland (5.0\%) and Hungary (4.3\%). Baseline characteristics of Swedish- born and foreign- born in relation to conventional cardiovascular risk factors (WC, leukocyte count, systolic BP, use of BP-lowering and lipid-lowering medication, diabetes mellitus, current smoking, high alcohol consumption, low physical activity) and socioeconomic factors (educational level, marital status) are presented in Table 1. Foreign-born subjects were younger, more often current smokers, diabetics, high alcohol consumers, and had more often low physical activity than those born in Sweden. During a mean follow-up of 15 years, a total of 764 individuals (325 men and 273 women) were hospitalized with HF as primary diagnosis. Of them, 166 (96 men and 70 women) had an incident MI before or concurrent with HF hospitalization during follow-up. The latter group was censored at the time of the infarction in the primary analysis.

Risk of HF hospitalizations in relation to immigrant status The overall analysis showed higher risk of HF hospitalization for foreign-born compared to Swedish- born. Adjusted for age and sex, foreign- born had a significantly higher risk for HF (HR: 1.44; 95\% CI, 1.14-1.82) compared to Swedish-born. This increased risk remained (HR: 1.37; 1.08-1.73) after adjustment for other possible confounders, Table 2. If cases with MI before or concurrent with HF hospitalization $(\mathrm{n}=166)$ were included in the analysis, the risk for HF hospitalization among foreign-born (HR: 1.24; 1.01-1.54) was only marginally changed, Table 2 .

In the final model, age and male sex, increased $\mathrm{WC}$, leukocyte count, systolic BP, use of BP-lowering medication, diabetes, smoking, high alcohol consumption, low physical activity, low educational level were independently associated with an increased risk for HF, Table 2.

\section{Interaction between immigrant status and other risk factors on incidence of $\mathrm{HF}$}

Interaction terms between covariates were added in the final Cox's proportional hazards model with adjustment for possible confounders. There was a statistically significant interaction between immigrant status and WC $(p$ $<0.001$ ) on incidence of HF. There were no other significant interactions between immigrant status and risk factors.

To further explore the interaction between country of birth and WC, WC was stratified into normal and high WC in men and women, respectively [22], Table 3 and Figure 1. After stratification for WC, a significant higher risk of $\mathrm{HF}$ was only observed in foreign-born with high WC (HR: 2.11; 95\% CI, 1.62-2.76), while foreign-born with normal WC had similar risk (HR: 1.17; 0.85-1.60) as compared to Swedish natives with normal WC.

Table 1 Characteristics of subjects in the Malmö diet and cancer (MDC) cohort in relation to immigration status, at the baseline examination 1991-1996

\begin{tabular}{|c|c|c|c|}
\hline MDC $(\mathrm{N}=26,559)$ & $\begin{array}{l}\text { Swedish-born } \\
(\mathrm{n}=23,430)\end{array}$ & $\begin{array}{l}\text { Foreign-born } \\
(\mathrm{n}=3,129)\end{array}$ & $P$ value \\
\hline Mean age (years) & $58.2 \pm 7.6$ & $56.9 \pm 7.2$ & $<0.001$ \\
\hline Men (\%) & 38.4 & 39.1 & $<0.001$ \\
\hline Waist circumference $(\mathrm{cm})$ & $84 \pm 15$ & $85 \pm 10$ & $<0.001$ \\
\hline $\mathrm{SBP}(\mathrm{mmHg})$ & $141 \pm 20$ & $140 \pm 20$ & $<0.001$ \\
\hline $\mathrm{DBP}(\mathrm{mmHg})$ & $86 \pm 10$ & $85 \pm 13$ & 0.426 \\
\hline Leukocytes $\left(10^{9} / \mathrm{L}\right)$ & $6.4 \pm 2.2$ & $6.5 \pm 3.5$ & 0.183 \\
\hline Hypertension (\%) & 40.5 & 38.6 & $<0.001$ \\
\hline Use of BP-lowering medications (\%)* & 41.1 & 40.1 & $<0.001$ \\
\hline Use of lipid-lower medications (\%) & 2.4 & 2.1 & 0.279 \\
\hline Diabetes (\%) & 2.8 & 3.3 & $<0.001$ \\
\hline Current smoker (\%) & 27.9 & 31.0 & $<0.001$ \\
\hline High alcohol consumption (\%) & 4.2 & 5.2 & 0.015 \\
\hline Low physical activity (\%) & 24.5 & 28.4 & $<0.001$ \\
\hline Low educational level (\%) & 42.1 & 35.3 & $<0.001$ \\
\hline Married (\%) & 65.7 & 62.3 & $<0.001$ \\
\hline
\end{tabular}

All other values are mean $\pm \mathrm{SD}$, unless otherwise stated. * Use of blood pressure (BP)-lowering medications is calculated as proportions of hypertensives in each group ( $\mathrm{n}=9488$ and $\mathrm{n}=1207$, respectively). 
Table 2 Final multivariate model for first hospitalization due to heart failure in the MDC cohort

\begin{tabular}{|c|c|c|c|c|}
\hline & $\begin{array}{c}\text { INCIDENT HF WITHOUT PRIOR MI } \\
\text { HRt }(95 \% \mathrm{Cl})\end{array}$ & $p$ value & $\begin{array}{l}\text { ALL INCIDENT HF } \\
\text { HRt }(95 \% \mathrm{Cl})\end{array}$ & $p$ value \\
\hline Foreign-born (yes vs no) & $1.37(1.08-1.73)$ & 0.009 & $1.24(1.01-1.54)$ & 0.045 \\
\hline Age (per 1 year) & $1.11(1.09-1.12)$ & $<0.001$ & $1.11(1.09-1.12)$ & $<0.001$ \\
\hline Male sex (yes vs no) & $1.71(1.44-2.03)$ & $<0.001$ & $1.68(1.45-1.95)$ & $<0.001$ \\
\hline Waist circumference $($ per $5 \mathrm{~cm}$ ) & $1.03(1.02-1.04)$ & $<0.001$ & $1.03(1.02-1.04)$ & $<0.001$ \\
\hline Systolic blood pressure (per $10 \mathrm{~mm} \mathrm{Hg}$ ) & $1.13(1.09-1.18)$ & $<0.001$ & $1.15(1.11-1.20)$ & $<0.001$ \\
\hline Leukocyte count (per $10^{9} / \mathrm{L}$ ) & $1.02(1.01-1.03)$ & 0.005 & $1.02(1.01-1.03)$ & 0.001 \\
\hline Use of BP-lowering medications (yes vs no) & $2.02(1.69-2.41)$ & $<0.001$ & $2.03(1.74-2.37)$ & $<0.001$ \\
\hline Use of lipid-lowering medications (yes vs no) & $1.10(0.73-1.63)$ & 0.658 & $1.43(1.06-1.94)$ & 0.021 \\
\hline Diabetes mellitus (yes vs no) & $2.78(2.12-3.65)$ & $<0.001$ & $2.80(2.22-3.54)$ & $<0.001$ \\
\hline Smoking (yes vs no) & $1.94(1.63-2.32)$ & $<0.001$ & $2.11(1.81-2.46)$ & $<0.001$ \\
\hline High alcohol consumption (yes vs no) & $1.53(1.10-2.14)$ & 0.012 & $1.40(1.03-1.91)$ & 0.032 \\
\hline Low physical activity (yes vs no) & $1.27(1.07-1.52)$ & 0.008 & $1.26(1.07-1.47)$ & 0.004 \\
\hline Unmarried (yes vs no) & $1.21(1.02-1.44)$ & 0.028 & $1.15(0.98-1.34)$ & 0.081 \\
\hline Low educational level (yes vs no) & $1.18(1.00-1.39)$ & 0.050 & $1.23(1.06-1.42)$ & 0.005 \\
\hline
\end{tabular}

Hazard ratio (HR)† in the final model. $\mathrm{Cl}$, confidence interval.

\section{Case fatality}

Thirty-two (4.2\%) subjects died within 1-month after the HF hospitalization and 95 (18.9\%) had died one year after the HF. After adjustment for age, sex and year of the HF hospitalization, the immigrants group tended to have lower one-month and one-year mortality (HR: 0.20 ; 95\% CI: $0.03-1.44, p=0.109$ and HR: 0.47 ; $0.22-$ $1.01, p=0.053$, respectively).

\section{Discussion}

The present population-based cohort study shows that being foreign-born is associated with significantly higher risk for HF hospitalization, independent of several biological, lifestyle and socioeconomic risk factors. The results are in line with prior studies on immigration status and cardiovascular disease (CVD) in Sweden $[14,16,18]$. However, the present results also show that the increased risk among immigrants is modified by the presence of other risk factors. There was a significant interaction between WC and immigrant status on risk of HF hospitalizations, and the increased incidence was mainly observed in those with high WC.
One possible explanation for the increased risk of HF hospitalization in foreign-born compared to Swedishborn might be influences from their country of birth. Compared to $15.6 \%$ being foreign-born in whole Malmö [18], the proportion of foreign-born in the MDC cohort were $11.8 \%$ of all study subjects. This group mainly came from Denmark, Former Yugoslavia, Finland, Germany, Poland and Hungary. The majority of these countries have higher incidence of CVD compared to Sweden [26,27]. Since most cases of HF are caused by hypertension or CHD, the high CVD risk in their country of origin might partly explain the increased risk of hospitalization due to HF. It has often been suggested that socioeconomic differences could explain the high morbidity in immigrant groups. Studies have shown that residential areas in Malmö with high proportion of immigrants and low socioeconomic status have high incidence of CVD $[28,29]$. However, the immigrants in this cohort study had higher education levels than those born in Sweden and the present results remained significant also after adjustments for education and marital status. Socioeconomic differences therefore seem to be

Table 3 Interaction between immigration status and waist circumference (WC) on incidence of HF in the MDC cohort

\begin{tabular}{lcc}
\hline Interaction term Immigrant status*WC & $\begin{array}{c}\text { INCIDENT HF WITHOUT PRIOR MI } \\
\text { HRt (95\% Cl) }\end{array}$ & $\begin{array}{c}\text { ALL INCIDENT HF } \\
\text { HRT (95\% CI) }\end{array}$ \\
\hline Swedish-born with normal WC (reference) & $P<0.001$ & $P<0.001$ \\
\hline Swedish- born with high WC & 1 & 1 \\
\hline Foreign- born with normal WC & $1.67(1.38-2.02)$ & $1.71(1.45-2.03)$ \\
\hline Foreign- born with high WC & $1.17(0.85-1.60)$ & $1.06(0.79-1.42)$ \\
\hline
\end{tabular}

Hazard ratio HRt adjusted for age, sex, civil status, education level, smoking habits, alcohol consumption, physical activities, BP-lowering medication, lipidlowering medication, systolic BP, leukocyte count and diabetes mellitus. Cl, confidence interval. 


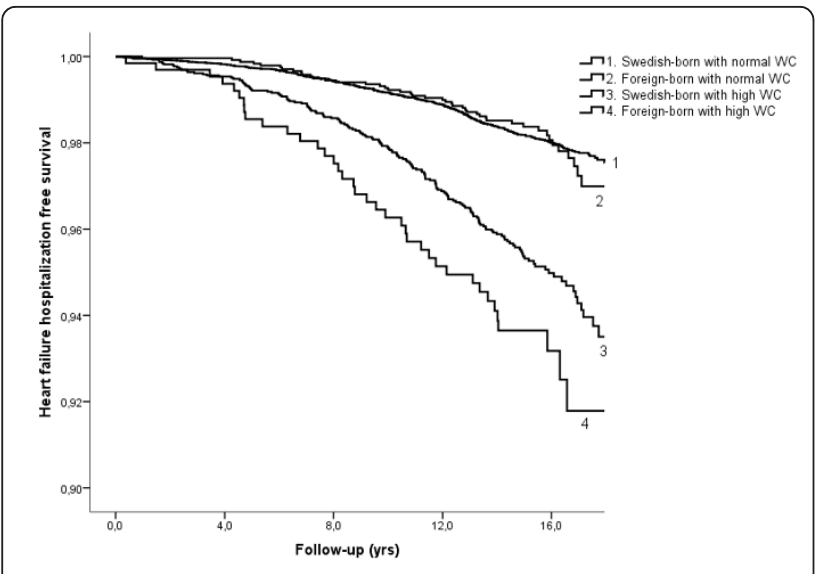

Figure 1 Heart failure hospitalization free survival in relation to immigration status and high/normal waist circumference

an insufficient explanation for the increased incidence of HF hospitalizations in foreign-born.

In the present study, a wide range of biological and life-style risk factors were independently associated with risk for HF. The increased HF risk for foreign-born still remained after adjustment for these risk factors. There was a significant interaction between immigrant status and WC on incidence of HF, which showed that the highest risk for HF was limited to foreign-born with high WC. As a heterogeneous group there are substantial differences among immigrants to Sweden by country of origin [30,31]. A previous cross-sectional study, based on the MDC cohort, found that women born in Hungary, Poland and Germany had higher WHR compared to Swedish-born women, after taking age, height, smoking, physical activity, occupation and percentage of body fat into account [31]. In men, WHR was increased in participants from Yugoslavia, Germany and Finland [31]. In that study length of residence in Sweden was found inversely associated with central adiposity in immigrants and it was concluded that immigrants may be at higher risk of obesity-related comorbidities [31].

Several studies have shown that increased abdominal adiposity is strongly associated with cardiovascular risks $[10,32,33]$. Inadequate exercise, over-intake of food or alcohol, metabolic imbalance and genetic abnormalities could cause high WC. The high WC influence known risk factors, e.g., dyslipidemia, hypertension, glucose intolerance, inflammation markers $[13,34,35]$, that increase risk of developing HF.

Foreign-born tended to have lower mortality after HF compared to Swedish- born, but the difference did not reach statistical significance. This might be explained by the so-called "obesity paradox", since the foreign-born had higher WC than Swedish-born and overweight and high WC paradoxically have been associated with improved outcome among HF patients [36,37]. It has been reported that immigrants and native Swedish HF patients are quite similar in terms of symptoms, health care seeking, the distress level, physical function, emotional state and self care $[38,39]$. More immigrants than Swedes are referred to HF clinic after discharge for follow-ups [40], which could reduce mortality in this group.

\section{Strength and limitation}

The study used large numbers of subjects with a long follow-up period and identified large numbers of $\mathrm{HF}$ events $[19,21]$. The cardiovascular endpoints were retrieved from national registers, and studies have showed high case validity for HF and MI in the register data $[24,25]$.

A main limitation of the present study is lack of information on type and cause of HF. Previous studies have demonstrated that immigrants to Sweden have an increased incidence of CVD $[16,17]$. However, we can only speculate whether the increased risk of hospitalizations due to HF among immigrants in the present study was related to a reduced or normal ejection fraction. In addition, we were unable to include HF patients who only were treated as out-patients. The total incidence of $\mathrm{HF}$ is therefore underestimated and we cannot make any conclusion about less severe cases which often are treated as out-patients. The $40.8 \%$ participation rate in the MDC study questions the representativity of the population [41]. It was shown that non-participants had higher mortality rate than participants in the MDC cohort. However, there was no substantial difference when comparing baseline characteristics of subjects in the MDC study to a survey study from the Malmö city with participation rate of 75\% [41]. Another short-coming is that we were unable to study immigrants by country of origin due to limited number of HF events, however in a previous study based on the whole Malmö city population we found an increased incidence of $\mathrm{HF}$ hospitalizations in immigrants from Finland, Former Yugoslavia and Hungary [18].

The MDC study required participants to be able to speak Swedish language. One question is whether this group of immigrants is representative to all immigrants in the city. Among all subjects aged 45-73 years in the whole Malmö population, foreign- born had a significantly higher risk for HF (HR: 1.27; 95\% CL, 1.17-1.38) compared to Swedish-born after adjustment for age and sex. The corresponding HR in the MDC cohort was 1.44 (95\% CI; 1.14-1.82), and we therefore believe that the results can be generalized.

The choice of risk factors variables in the multivariate model can influence the results since adjustments for risk factors that are mediators in the causal pathway will 
underestimate of the relation, while leaving out genuine confounders will overestimate the result. The variables used for adjustments in the study, e.g., age, sex, smoking, hypertension, diabetes, abdominal obesity, alcohol consumption and physical activity are well known cardiovascular risk factors $[2,4,5,9,10,12,42,43]$. Educational level is a widely used measure of socioeconomic circumstances in epidemiologic studies, and is considered to be related to health outcome by its influence on lifestyle behaviors and value [44]. Low educational level has been reported to associate with higher cardiovascular risk $[45,46]$. Marital status has been found associated with HF $[7,47]$.

The lack of follow-up data regarding anthropometric measures and other risk factors in the present study is another issue to be discussed. It is possible that biological factors, e.g., blood pressure and WC changed during the follow-up. However, this is usually a slow process and one study found that adipose tissue distribution is stable through the lifespan [48]. Some subjects might change the status in terms of smoking, physical activity, alcohol consumption and marriage. It is unknown whether change of risk factors during the follow-up could be differential between immigrants and native Swedes.

\section{Conclusions}

In conclusion, immigrant status is associated with longterm risk of HF hospitalization, independently of hypertension and several life-style risk factors. A significant interaction between WC and immigrant status on incident HF was observed.

\begin{abstract}
Acknowledgements
This work and the Malmö Diet and Cancer study was supported by grants from the Swedish Cancer Society, the Swedish Research Council (Dnr 2011 3891), the Swedish Heart and Lung Foundation, the faculty of medicine, Uppsala University and Lund University, the Malmö city Council and by funds from the Region Skåne, Skåne University Hospital, Malmö and Lundströms Foundation.

Author details

${ }^{1}$ Department of Clinical Sciences, Cardiovascular Epidemiology, Skåne University Hospital, Lund University, 20502 Malmö, Sweden. ${ }^{2}$ Department of Women's and Children's Health, International Maternal and Child Health (IMCH), Uppsala University, 75185 Uppsala, Sweden.

\section{Authors' contributions \\ $\mathrm{YB}, \mathrm{GE}$ and $\mathrm{BH}$ constructed the concept and design of the project; $\mathrm{YB}$ performed the analysis and drafted the manuscript; $Y B, G E, B E$ and $B H$ participated in the analysis and interpretation of data and revised the manuscript critically. All authors approved the final manuscript to be published.}

\section{Competing interests}

Gunnar Engström is employed as senior epidemiologist by AstraZeneca R\&D.

Received: 7 December 2011 Accepted: 26 March 2012

Published: 26 March 2012
References

1. Fox KF, Cowie MR, Wood DA, Coats AJ, Poole-Wilson PA, Sutton GC: New perspectives on heart failure due to myocardial. ischaemia. Eur Heart $J$ 1999, 20(4):256-262.

2. Cowie MR, Wood DA, Coats AJ, Thompson SG, Poole-Wilson PA, Suresh V, Sutton GC: Incidence and aetiology of heart failure; a population-based study. Eur Heart J 1999, 20(6):421-428.

3. Nieminen MS, Brutsaert D, Dickstein K, Drexler H, Follath F, Harjola VP, Hochadel M, Komajda M, Lassus J, Lopez-Sendon JL, Ponikowski P, Tavazzi L: EuroHeart Failure Survey II (EHFS II): a survey on hospitalized acute heart failure patients: description of population. Eur Heart J 2006, 27(22):2725-2736.

4. Lloyd-Jones DM, Larson MG, Leip EP, Beiser A, D'Agostino RB, Kannel WB, Murabito JM, Vasan RS, Benjamin EJ, Levy D: Lifetime risk for developing congestive heart failure: the Framingham Heart Study. Circulation 2002, 106(24):3068-3072.

5. Levy D, Larson MG, Vasan RS, Kannel WB, Ho KK: The progression from hypertension to congestive heart failure. JAMA 1996, 275(20):1557-1562.

6. Christensen S, Mogelvang R, Heitmann M, Prescott E: Level of education and risk of heart failure: a prospective cohort study with echocardiography evaluation. Eur Heart J 2011, 32(4):450-458.

7. Chung ML, Lennie TA, Riegel B, Wu JR, Dekker RL, Moser DK: Marital status as an independent predictor of event-free survival of patients with heart failure. Am J Crit Care 2009, 18(6):562-570.

8. Engström G, Hedblad B, Tyden P, Lindgarde F: Inflammation-sensitive plasma proteins are associated with increased incidence of heart failure: a population-based cohort study. Atherosclerosis 2009, 202(2):617-622.

9. Kannel WB, Hjortland M, Castelli WP: Role of diabetes in congestive heart failure: the Framingham study. Am J Cardiol 1974, 34(1):29-34.

10. Kenchaiah S, Evans JC, Levy D, Wilson PW, Benjamin EJ, Larson MG, Kannel WB, Vasan RS: Obesity and the risk of heart failure. N Engl J Med 2002, 347(5):305-313.

11. Bleumink GS, Knetsch AM, Sturkenboom MC, Straus SM, Hofman A, Deckers JW, Witteman JC, Stricker BH: Quantifying the heart failure epidemic: prevalence, incidence rate, lifetime risk and prognosis of heart failure The Rotterdam Study. Eur Heart J 2004, 25(18):1614-1619.

12. He J, Ogden LG, Bazzano LA, Vupputuri S, Loria C, Whelton PK: Risk factors for congestive heart failure in US men and women: NHANES I epidemiologic follow-up study. Arch Intern Med 2001, 161(7):996-1002.

13. Bjorntorp P: Obesity and adipose tissue distribution as risk factors for the development of disease. A review. Infusionstherapie 1990, 17(1):24-27.

14. Gadd M, Johansson SE, Sundquist J, Wandell P: Morbidity in cardiovascular diseases in immigrants in Sweden. J Intern Med 2003, 254(3):236-243.

15. Gadd M, Johansson SE, Sundquist J, Wandell P: Are there differences in all-cause and coronary heart disease mortality between immigrants in Sweden and in their country of birth? A follow-up study of total populations. BMC Public Health 2006, 6:102.

16. Hedlund $E$, Lange $A$, Hammar N: Acute myocardial infarction incidence in immigrants to Sweden. Country of birth, time since immigration, and time trends over 20 years. Eur J Epidemiol 2007, 22(8):493-503.

17. Khan FA, Zia E, Janzon L, Engström G: Incidence of stroke and stroke subtypes in Malmo, Sweden, 1990-2000: marked differences between groups defined by birth country. Stroke 2004, 35(9):2054-2058.

18. Borne Y, Engström G, Essen B, Sundquist J, Hedblad B: Country of birth and risk of hospitalization due to heart failure: a Swedish populationbased cohort study. Eur J Epidemiol 2011, 26(4):275-283.

19. Berglund G, Elmstahl S, Janzon L, Larsson SA: The Malmo Diet and Cancer Study. Design and feasibility. J Intern Med 1993, 233(1):45-51.

20. Melander $O$, Newton-Cheh C, Almgren P, Hedblad B, Berglund G, Engstrom G, Persson M, Smith JG, Magnusson M, Christensson A, Struck J, Morgenthaler NG, Bergmann A, Pencina MJ, Wang TJ: Novel and conventional biomarkers for prediction of incident cardiovascular events in the community. JAMA 2009, 302(1):49-57.

21. Smith JG, Newton-Cheh C, Almgren P, Struck J, Morgenthaler NG, Bergmann A, Platonov PG, Hedblad B, Engstrom G, Wang TJ, Melander O: Assessment of conventional cardiovascular risk factors and multiple biomarkers for the prediction of incident heart failure and atrial fibrillation. J Am Coll Cardiol 2009, 56(21):1712-1719.

22. Lean ME, Han TS, Morrison CE: Waist circumference as a measure for indicating need for weight management. BMJ 1995, 311(6998):158-161.

23. Rosvall M, Ostergren PO, Hedblad B, Isacsson SO, Janzon L, Berglund G: Occupational status, educational level, and the prevalence of carotid 
atherosclerosis in a general population sample of middle-aged Swedish men and women: results from the Malmo Diet and Cancer Study. Am J Epidemiol 2000, 152(4):334-346

24. Ingelsson $E$, Arnlöv J, Sundström J, Lind L: The validity of a diagnosis of heart failure in a hospital discharge register. Eur J Heart Fail 2005, 7:787-791

25. Hammar N, Alfredsson L, Rosen M, Spetz CL, Kahan T, Ysberg AS: A national record linkage to study acute myocardial infarction incidence and case fatality in Sweden. Int J Epidemiol 2001, 30(Suppl 1):S30-S34.

26. Sans S, Kesteloot H, Kromhout D: The burden of cardiovascular diseases mortality in Europe. Task Force of the European Society of Cardiology on Cardiovascular Mortality and Morbidity Statistics in Europe. Eur Heart J 1997, 18(12):1231-1248.

27. Kesteloot H: Nutrition and health. Eur Heart J 1992, 13(1):120-128.

28. Engstrom $G$, Goransson M, Hansen $O$, Hedblad B, Tyden P, Todt $T$, Janzon L: Trends in long-term survival after myocardial infarction: less favourable patterns for patients from deprived areas. J Intern Med 2000, 248(5):425-434.

29. Tyden P, Hansen O, Engström G, Hedblad B, Janzon L: Myocardial infarction in an urban population: worse long term prognosis for patients from less affluent residential areas. J Epidemiol Community Health 2002, 56(10):785-790.

30. Lindstrom M, Sundquist $K$ : The impact of country of birth and time in Sweden on overweight and obesity: a population-based study. Scand J Public Health 2005, 33(4):276-284.

31. Lahmann PH, Lissner L, Gullberg B, Berglund G: Differences in body fat and central adiposity between Swedes and European immigrants: The Malmö Diet and Cancer Study. Obes Res 2000, 8(9):620-631.

32. Lakka TA, Lakka HM, Salonen R, Kaplan GA, Salonen JT: Abdominal obesity is associated with accelerated progression of carotid atherosclerosis in men. Atherosclerosis 2001, 154(2):497-504.

33. Nicklas BJ, Cesari M, Penninx BW, Kritchevsky SB, Ding J, Newman A, Kitzman DW, Kanaya AM, Pahor M, Harris TB: Abdominal obesity is an independent risk factor for chronic heart failure in older people. J Am Geriatr Soc 2006, 54(3):413-420.

34. Poirier P, Lemieux I, Mauriege P, Dewailly E, Blanchet C, Bergeron J, Despres JP: Impact of waist circumference on the relationship between blood pressure and insulin: the Quebec Health Survey. Hypertension 2005, 45(3):363-367.

35. Bastard JP, Jardel C, Delattre J, Hainque B, Bruckert E, Oberlin F: Evidence for a link between adipose tissue interleukin- 6 content and serum Creactive protein concentrations in obese subjects. Circulation 1999, 99(16):2221-2222.

36. Clark AL, Fonarow GC, Horwich TB: Waist circumference, body mass index, and survival in systolic heart failure: the obesity paradox revisited. $J$ Card Fail 2011, 17(5):374-380.

37. Oreopoulos A, Padwal R, Kalantar-Zadeh K, Fonarow GC, Norris CM, McAlister FA: Body mass index and mortality in heart failure: a metaanalysis. Am Heart J 2008, 156(1):13-22.

38. Hedemalm A, Schaufelberger M, Ekman I: Symptom recognition and health care seeking among immigrants and native Swedish patients with heart failure. BMC Nurs 2008, 7:9.

39. Hedemalm A, Schaufelberger M, Ekman I: Reported adherence and social support among immigrants compared to native Swedes. J Immigr Minor Health 2009, 12(1):124-131.

40. Hedemalm A, Schaufelberger M, Ekman I: Equality in the care and treatment of immigrants and native Swedes-a comparative study of patients hospitalised for heart failure. Eur J Cardiovasc Nurs 2008, 7(3):222-228.

41. Manjer J, Carlsson S, Elmstahl S, Gullberg B, Janzon L, Lindstrom M, Mattisson I, Berglund G: The Malmo Diet and Cancer Study: representativity, cancer incidence and mortality in participants and nonparticipants. Eur J Cancer Prev 2001, 10(6):489-499.

42. Yusuf S, Hawken S, Ounpuu S, Dans T, Avezum A, Lanas F, McQueen M, Budaj A, Pais P, Varigos J, Lisheng L: Effect of potentially modifiable risk factors associated with myocardial infarction in 52 countries (the INTERHEART study): case-control study. Lancet 2004, 364(9438):937-952.

43. Klatsky AL, Chartier D, Udaltsova N, Gronningen S, Brar S, Friedman GD, Lundstrom RJ: Alcohol drinking and risk of hospitalization for heart failure with and without associated coronary artery disease. Am J Cardiol 2005, 96(3):346-351.
44. Liberatos $P$, Link BG, Kelsey JL: The measurement of social class in epidemiology. Epidemiol Rev 1988, 10:87-121.

45. Mulcahy R, Daly L, Graham I, Hickey N: Level of education, coronary risk factors and cardiovascular disease. Ir Med J 1984, 77(10):316-318

46. Hinkle LE Jr, Whitney LH, Lehman EW, Dunn J, Benjamin B, King R, Plakun A, Flehinger B: Occupation, education, and coronary heart disease. Risk is influenced more by education and background than by occupational experiences, in the Bell System. Science 1968, 161(838):238-246.

47. Luttik ML, Jaarsma T, Veeger $N$, van Veldhuisen DJ: Marital status, quality of life, and clinical outcome in patients with heart failure. Heart Lung 2006, 35(1):3-8

48. Katzmarzyk PT, Perusse L, Malina RM, Bouchard C: Seven-year stability of indicators of obesity and adipose tissue distribution in the Canadian population. Am J Clin Nutr 1999, 69(6):1123-1129.

\section{Pre-publication history}

The pre-publication history for this paper can be accessed here: http://www.biomedcentral.com/1471-2261/12/20/prepub

doi:10.1186/1471-2261-12-20

Cite this article as: Borné et al: Immigrant status and increased risk of heart failure: the role of hypertension and life-style risk factors. $B M C$ Cardiovascular Disorders 2012 12:20

\section{Submit your next manuscript to BioMed Central and take full advantage of:}

- Convenient online submission

- Thorough peer review

- No space constraints or color figure charges

- Immediate publication on acceptance

- Inclusion in PubMed, CAS, Scopus and Google Scholar

- Research which is freely available for redistribution
C Biomed Central 